\title{
Leader and Organizational Behavioral Integrity and Follower Behavioral Outcomes: The Role of Identification Processes
}

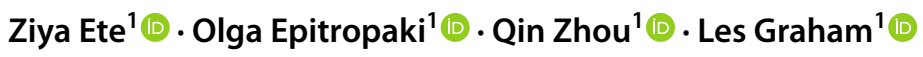

Received: 29 January 2020 / Accepted: 29 December 2020 / Published online: 27 January 2021

(c) The Author(s) 2021

\begin{abstract}
This paper investigates the concept of behavioral integrity from three important foci in organizational settings: i.e., leader, organization, and follower. Drawing from theories of behavioral integrity, social learning, and social identity, we examine the effects of leader and organizational behavioral integrity on follower behavioral integrity and organizational citizenship behavior via follower identification with leader and with organization, respectively. To test our hypotheses, we used data from three studies. Studies 1 and 2 were online experiments ( $N=211$ and $N=200$, respectively) in which behavioral integrity was manipulated in written scenarios to explore the proposed causal relationships. Study 3 was a multisource field study that tested a mediation model using matched data collected from 280 employees and their co-workers from a Fire and Rescue Service in the United Kingdom. The findings provide partial support for our hypothesized model and highlight the importance of examining multiple foci of behavioral integrity as well as the role of follower identification as key mediating mechanisms of the relationship between leader and organizational behavioral integrity and follower behavioral outcomes. Theoretical and practical implications are discussed.
\end{abstract}

Keywords Behavioral integrity $\cdot$ Follower identification $\cdot$ Organizational citizenship behavior

$$
\begin{aligned}
& \text { "Appear as you are. Be as you } \\
& \text { appear." — Rumi. }
\end{aligned}
$$

\section{Introduction}

Highly publicized corporate ethical scandals have highlighted the need to recognize the importance of ethics and virtues within organizations and the importance of studying organizational actors' ethical behaviors (Brown et al. 2005; Brown and Treviño 2006; Kacmar et al. 2011). This line of research mainly aims to establish that organizations can

Ziya Ete

ziya.ete@durham.ac.uk

Olga Epitropaki

olga.epitropaki2@durham.ac.uk

Qin Zhou

qin.zhou@durham.ac.uk

Les Graham

1.n.graham@durham.ac.uk

1 Durham University Business School, Durham University, Millhill Lane, Durham DH1 3LB, UK encourage managers and employees to act ethically, leading to positive organizational outcomes (Ford and Richardson 1994; Kacmar et al. 2011; Ete et al. 2020). Among these studies, the concept of integrity, an important aspect of ethics and virtues in organization, has been attracting increasing research attention (Bass and Steidlmeier 1999; Brown and Trevino 2006). Indeed, integrity has come to be considered essential, even an "axiom" for leadership effectiveness (Palanski and Yammarino 2009, p. 406; Sosik et al. 2019) and by extension, for organizational effectiveness (Parry and Proctor-Thomson 2002). Despite its importance, integrity research still suffers from limited theoretical explication and a relatively small number of empirical studies (Becker 1998; Davis and Rothstein 2006; Palanski and Yammarino 2011). We aim to contribute to integrity research by examining the role of multiple foci of behavioral integrity on follower behavioral outcomes and further cast light on potential mediating mechanisms of this relationship.

To provide an accurate empirical examination about integrity, it is essential to define the construct first (Bauman 2013). Simons (2002) introduced the concept of behavioral integrity (BI), which refers to the "perceived pattern of alignment between an actor's words and deeds" (p. 19). The 
construct particularly focuses on both the perceived match between espoused and enacted values and perceived promise-keeping (Simons 2002). Palanski and Yammarino (2007) view BI within the framework of moral philosophy and classify it as an adjunctive virtue, which is necessary for good character and ethical conduct. BI is particularly critical in contemporary organizations that operate in a dynamic environment, because managers and organizations are challenged to act consistently in word and deed and keep their promises while employees need certainty and predictability (Simons 2002). Empirical research has shown leader BI positively relates to leader's effectiveness (Palanski et al. 2015), trust in leader (Simons et al. 2007; Palanski and Yammarino 2011), and satisfaction with leader (Palanski and Yammarino 2011). Although these studies have provided substantial evidences that BI has important implications in an organizational setting, the construct is still in its infancy (Simons et al. 2011) and several important gaps remain unaddressed.

First, BI has been explored exclusively at the level of individual actors, namely, leaders (Palanski and Yammarino 2009). However, behavioral integrity theory (Simons 2002) proposes that the construct of BI can apply to collective actors such as organizations. In their review, Palanski and Yammarino (2009) stressed that the acting entity of BI may be a person or a collective unit and further argued that "the integrity of the acting entity (either individual, group, or organization, respectively) is a property of the acting entity (either individual, group, or organization, respectively) and cannot be attributed to any other acting entity at any other level" (p. 408). Accordingly, organizational BI is defined as the followers' perception of alignment between an organization's statements and actions (Simons 2002; Palanski and Yammarino 2009). Current conceptual work on BI has urged researchers to look at multiple BI foci and take a broader perspective on BI that goes beyond direct supervisors and further include the BI of the organization (Palanski and Yammarino 2009; Simons et al. 2015). Yet, empirical work remains scant, missing the opportunity to understand the impact of different referents of BI on employee outcomes. Our research aims to fill this gap and examine both the leader and the organization as important BI foci. We expect leader BI and organizational BI to be related but distinct constructs and examine both foci of BI as key antecedents of follower outcomes.

Second, although prior research has examined BI as an influential characteristic of leaders that enhances followers' in- role performance (Leroy et al. 2012) and attitudes such as job satisfaction (Simons et al. 2007), organizational commitment (Fritz et al. 2012) and engagement (Hewlin et al. 2017), research on the role of BI at the leader and organization level as a facilitator of unprescribed and extra- role behaviors such as ethical behaviors and citizenship behaviors remains limited (Davis and Rothstein 2006; Simons et al.
2015). This is an important omission because organizations increasingly rely on their employees to demonstrate these behaviors in the workplace to achieve organizational effectiveness (Parry and Proctor-Thomson 2002; Wang et al. 2019). To fill this gap, we examined BI and organizational citizenship behaviors (OCB) as follower prosocial behavioral outcomes in this study. Both of these follower outcomes are considered important by Simons' (2002) and Palanski and Yammarino's (2009) theoretical works, but they have received little empirical research attention (e.g., Dineen et al. 2006; Kannan-Narasimhan and Lawrence 2012; Palanski and Yammarino 2011). Follower BI is defined as the perception of organizational members' consistency between their words and deeds indicates good character and ethical conduct among members (Palanski and Yammarino 2007). OCB is defined as organizational members' "contributions to the maintenance and enhancement of the social and psychological context that support task performance" (Organ 1997, p. 91). More recently Simons et al. (2015) had called for investigating the substantial impact of different referents of BI on follower prosocial behavioral outcomes to better understand this relationship. Our research aims to answer this call and cast further light on the role of BI in promoting followers' ethical and extra-role behaviors by examining both leader BI and organizational BI as important predictors of follower BI and follower OCBs.

Third, research has been primarily focused on trust in and satisfaction with leader as the mechanisms of influence for leader BI on follower outcomes (e.g., Palanski and Yammarino 2011; Hinkin and Schriesheim 2015). Yet, this perspective is limited in explaining how and why the BI of both leaders and organizations influence followers. Simons et al. (2015, p. 841) pointed out the need for further research to unpack the "unmediated path" that links BI to follower extra-role behaviors (e.g., follower BI and OCB) as it is important to know whether different mechanisms of impact are represented in this relationship. To cast additional light on the role of BI in leader/organization-employee relationships and to investigate the impact of different BI referents on follower outcomes, we utilize social identity theory (Tajfel and Turner 1979) which focuses on followers' identification as a "root" construct that helps us understand how individuals define their relations with other entities at work (Sluss and Ashforth 2007). Accordingly, we focus on two identification pathways in relation to BI and examine leader identification as a consequence of leader BI and organizational identification as a consequence of organizational BI.

The primary purpose of this study is to address these issues in the literature by examining BI construct with different referents and how BI of these different referents influences follower behavioral outcomes. Specifically, our research aims to empirically focus on the role of $\mathrm{BI}$ in promoting followers' ethical (i.e., BI) and extra-role behaviors 
Fig. 1 The research hypothesized model. Note. $\mathrm{BI}=$ behavioral integrity, $\mathrm{OCBO}=$ organizational citizenship behavior toward organization

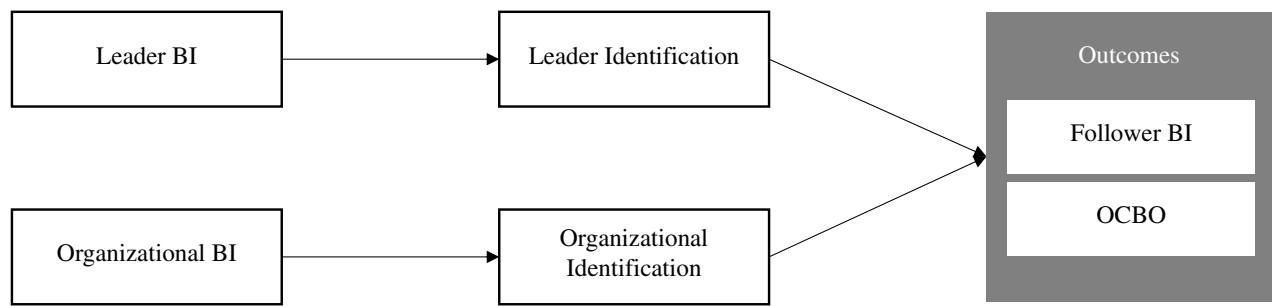

(i.e., OCB) by examining both leader BI and organizational $\mathrm{BI}$ as important predictors of these follower outcomes and the mediating role of follower identification in these relationships. Figure 1 depicts the conceptual model of the present research. The findings from this research model expand the boundaries of the BI construct by applying a multifoci perspective and examining the impact of leader BI and organizational BI simultaneously. This research also broadens the applications of BI in organizational settings by explicating the role of leader and organizational $\mathrm{BI}$ in predicting follower behavioral outcomes. Finally, it attempts to offer a more comprehensive understanding of the process through which leader and organizational BI influence employee behavioral outcomes by adopting a social identity lens (Tajfel and Turner 1986) and examining leader and organizational identification as key mediators of these relationships.

We begin by reviewing the literature about leader BI and organizational BI. Next, we build key hypotheses based on social learning and social identity theories and examine the proposed relationships with data from three studies (two experiment studies and one field study) that were designed to build upon one another. We conclude with a general discussion of the findings from all three studies, theoretical and practical implications, limitations, and future research directions.

\section{Leader and Organizational Behavioral Integrity}

Leader BI captures the perceived alignment between a target's statements and actions (Simons 2002). The construct has two components: the perceived match between espoused and enacted values and perceived promise-keeping (Simons 2002). In an organizational context, leader BI entails members' perception about whether the leaders represent themselves accurately in terms of their values, beliefs, priorities, and expectations-in other words, whether they "walk the talk." Moreover, BI's promise-keeping dimension includes the perception of behavioral adherence to psychological contracts and retaining commitments (Simons 2002). Thus, BI provides reliability (Simons et al. 2007) and credibility (Holmes and Parker 2017) to the leader. The positive effects of leader BI on leader-follower relationships and leadership effectiveness have been confirmed in recent meta-analytical reviews (see Simons et al. 2015).

Following the empirical evidence that indicates leader BI plays an important role in the leader-follower relationship, we argue that organizational BI could also play a role in the organization-employee relationship. Simons (2002) argues that employees can be attuned to BI-relevant cues independently for the organization through human resources practices, psychological contracts, corporate mission statements, organizational value statements and policies. Palanski and Yammarino (2009) also distinguished between the BI of different acting entities (e.g., leader, organization) and argued employees can develop varying levels of BI perceptions for these entities, which in turn can have significant implications for their behaviors at work (Palanski and Yammarino 2009). Moreover, the existing literature that examines the organization-employee relationship has been challenging the current focus on the dyadic leader-employee relationship as it fails to capture the full extent of the social context in an organization (Alcover et al. 2017). Acknowledging employees can build multiple relations with diverse organizational agents (e.g., the organization, supervisors, or co-workers), the prior studies have provided sufficient support for how these agents influence employees' attitudes and behaviors independently in terms of social exchange (Tekleab and Chiaburu 2011), trust (Robinson 1996), identification (Epitropaki 2013), and citizenship behaviors (Ilies et al. 2007). Undeniably, leaders are key organizational representatives and their acting with integrity can positively reflect on employees' assessment of the integrity of the organizational collective. However, there are organizational-level practices and systems (such as HR selection processes, corporate communications, renumeration practices, among others) that are not in the direct leader's sphere of influence but can still be viewed by employees as indications of their organization's consistency and integrity. Taken together, considering the conceptual support and the gaps in the literature, we adopt a multifoci view and examine the effects of leader BI and organization $\mathrm{BI}$ as separate independent variables on follower outcomes.

In the next section, we examine how leader BI and organizational BI influence followers' identification with leader and with organization, and then how they predict followers' behaviors in terms of follower BI and OCBs. To examine 
these relationships, we introduce three studies and present theories and hypotheses within in each study.

\section{Study 1}

Identification is rooted in social identity theory (Tajfel and Turner 1979) and refers to an individual's perceived 'oneness' with a person (i.e., leader) or with a group (i.e., organization) (Ashforth and Mael 1989). It is evident when an individual's belief about the target becomes self-referential or self-defining (Pratt 1998). In the literature, identification has been mainly discussed in two forms: leader identification as a form of personal identification and organizational identification as a form of social identification. Research is increasingly acknowledging the importance of these two forms in terms of their influence on followers' cognition, affect, and behavior (Ashforth et al. 2008). Utilizing social identity theory, Study 1 tests the relationship between BI and identification in order to examine the role of leader BI on leader identification as well as the role of organizational $\mathrm{BI}$ on organizational identification.

\section{Leader Behavioral Integrity and Leader Identification}

Leader identification can be defined as perceived oneness with a leader, where one defines oneself in terms of the leader (Ashforth et al. 2015). To describe the determinants of followers' identification with their leader, Ashforth et al. (2015) proposed that the identification process is the result of followers' deliberately selecting a target who is attractive, accountable, and trustworthy and who displays desirable attributes in terms of values, behaviors, and abilities. Existing leadership theories also acknowledge that followers are more likely to identify with their leaders when they see them as trustworthy, attractive, and credible role models through them being honest and displaying integrity (Kark et al. 2003; Avolio et al. 2004). Leader BI indicates word and deed alignment and following up on commitments, which strengthen the reliability of a leader's words, enhances trustworthiness, and provides credibility to a leader (Simons et al. 2011; Holmes and Parker 2017). In this sense, we assume that leaders with a high level of BI would be seen as attractive, reliable role models and that followers would be likely to identify with these leaders. Moreover, the process of identification is based on open interaction and knowledge about the target (Ashforth et al. 2015). Leader BI is shaped by the extent to which leaders are consistent and transparent in their communication with followers about what they value, think, or expect (Vogelgesang et al. 2013). Thus, BI serves as source of information for followers to get to know their leader better and in turn may facilitate the leader identification process.
Based on the above discussion, first, leader identification literature proposes that followers identify with attractive and trustworthy leaders and that open communication with leader facilitates this process. Second, Simons' (2002) behavioral integrity theory suggests that $\mathrm{BI}$ is a desirable attribute that provides trust and credibility to leaders and allows leaders to clearly and consistently demonstrate their values to subordinates. Thus, these two bases provide the context and explanation for why followers would identify with their leader who is high in BI. Accordingly, we propose the following hypothesis:

H1a Leader BI will have a positive relationship with leader identification.

\section{Organizational Behavioral Integrity and Organizational Identification}

Organizational identification is defined as the perception of oneness with or belongingness to an organization, whereby individuals consider themselves members of the organization (Ashforth and Mael 1992). According to social identity theory (Tajfel and Turner 1979), there are two components of social identification: first, the perception of oneness or belongingness, which is the cognitive part; and second, the feeling of pride and meaningfulness in membership, which is the affective part. When employees acknowledge being part of the organization, they feel attached and find self-importance in their membership (Ashforth and Mael 1992). In the literature, organizational identification has been viewed as one of the most important mechanisms to understand the employee-organization relationship (Hogg and Terry 2000). Therefore, drawing on social identity theory, we examine the role organizational BI in facilitating organizational identification.

There are several reasons to propose that organizational BI predicts employees' organizational identification. First, members identify with an organization when they believe it represents socially valued characteristics because they feel proud to belong to this organization (Mael and Ashforth 1992; Pratt 1998). The more employees perceive organizational behaviors to be ethical, the more they identify with organization (Schrodt 2002). In the eyes of its members, an organization with BI keeps its promises to internal and external stakeholders, acts upon its norms, rules, and values, and behaves according to its mission and vision statements (Palanski and Yammarino 2009). Therefore, organizational BI enhances the organization's credibility, reputation for reliability, and ethicality in the eyes of its employees (Palanski and Yammarino 2009). Due to these ascriptions BI provides, members would be proud of their organization (Dutton et al. 1994) and, thus, it is more likely for them to identify with it. 
Second, the perception of BI is conceptually (Simons 2002) and empirically (Vogelgesang et al. 2013) related to communication clarity because the higher level of clarity and information sharing leads to more salient awareness of BI. Therefore, the more employees perceive organizational BI to be high, the more they feel informed about organizational procedures, norms, goals, or values. Once employees get to know their organizations better through organizational BI, they are more likely to identify with the organization, mainly because the organization's communication with members in terms of how organizational messages are communicated can influence organizational identification (Smidts et al. 2001). When employees are well informed of organizational goals, activities, and values, the organizational characteristics become more salient as targets with which to identify (Smidts et al. 2001). Finally, an organization with BI is consistent and apparent in its expectations from employees (Simons et al. 2015). A clear understanding of what is expected at work increases employees' knowledge of norms and values to be a respected member (Smidts et al. 2001). This understanding provides the basis for self-categorization (Turner et al. 1987) and contributes to employees' sense of belonging, therefore, it leads to organizational identification. Altogether, drawing upon social identity theory and organizational identification literature, we assume organizational BI will facilitate organizational identification and hypothesize the following:

H1b Organizational BI will have a positive relationship with organizational identification.

\section{Method}

\section{Participants and Procedures}

We recruited 211 United Kingdom full-time working professionals via Prolific, an online data collection platform. Participants received a small cash payment. Participants ranged in age from 19 to $67(M=39.4)$; $56 \%$ were women; $38 \%$ had a bachelor's degree (4-year), $22 \%$ were high school graduates, and $17 \%$ had associate college degrees (2-year). They were with a position of tenure with the organization on average of 7.3 years. Participants worked in the private sector $(52 \%)$ or in public organizations $(45 \%)$ and held nonmanagerial $(64.5 \%)$ or managerial positions $(35.5 \%)$.

In online experimental design, we created scenarios which manipulated the actions and behaviors of an imaginary leader and organization. The participants were randomly assigned to one of three leader-related scenarios: a high $(N=34)$, a low $(N=$
$35)$, or a neutral $(N=37)$ leader BI condition. Similarly, different participants were randomly assigned to one of three organizationrelated scenarios: a high $(N=34)$, a low $(N=35)$, or a neutral $(N$ $=36$ ) organizational BI condition (all scenarios are included in the Appendix). In each condition, participants were asked to read the scenario about a manager or an organization and imagine that they are working for this person or organization. After reading the manipulated scenarios, the participants were asked to rate their assigned leader's BI or organization's BI, as the manipulation checks. They were also asked to answer a series of questions that measured the dependent variables of leader or organizational identification.

\section{Measures}

\section{Independent Variables}

As a manipulation check, we measured participants' perceptions of the leader and organization's BI in the written scenarios with an eight-item perceived behavioral integrity scale developed by Simons et al. (2007). The scale consists of four items that represent promise-keeping behaviors and four items which capture the alignment between words and deeds. While the scale was originally designed to measure subordinates' perception of the managers, we also adapt it to measure organizational BI. The scale was modified slightly to reflect the name of the leader or organization in the scenarios. A sample item regarding leader BI is "There is a match between Alex's words and actions." A sample item for organizational $\mathrm{BI}$ is "If $\mathrm{ABC}$ promises something, it will happen." All items for the measures were rated on a five-point Likert scale ranging from 1 (strongly disagree) to 5 (strongly agree). The Cronbach's alphas for leader and organizational BI were .98 and .99 , respectively.

\section{Dependent Variables}

Leader identification and organizational identification were measured using Mael and Ashforth's (1992) six-item organizational identification scale. For leader identification, the scale was adapted to the leader as the target of identification. We modified items slightly to reflect the name of the leader and organization in the scenarios. A sample item for leader identification reads "I would feel insulted if other people criticize Alex" and for organizational identification reads "ABC's successes would be my successes." The Cronbach's alpha for leader identification was .81, and for organizational identification was .92. 


\section{Results}

We conducted a univariate analysis of variance (ANOVA) to see that the validity of manipulations for leader $\mathrm{BI}$ and organizational BI. Results from the ANOVA show that the manipulation was valid for leader BI $(F(2)=313.8$, $p<.001, \eta 2=.86)$; thus, demonstrating a difference between high $(M=4.77, \mathrm{SD}=.39)$, low $(M=1.50, \mathrm{~S} . \mathrm{D} .=$ $.49)$, and neutral $(M=3.75, \mathrm{SD}=.72)$ leader BI conditions. Results also show that manipulation was valid for organizational $\mathrm{BI}(F(2)=487, p<.001, \eta 2=.90)$, demonstrating a difference between high $(M=4.83, \mathrm{SD}=.34)$, low $(M=1.19, \mathrm{SD}=.44)$, and neutral $(M=3.73, \mathrm{SD}=.65)$ organizational BI conditions.

Second, we conducted ANOVA to test if there is a difference in follower identifications for leader BI and organizational BI conditions, respectively. Results indicated a significant difference in leader identification $(F(2)=19.5$, $p<.001, \eta 2=.27)$ between high $(M=3.68, \mathrm{SD}=.73)$, low $(M=2.67, \mathrm{SD}=.56)$, and neutral $(M=3.17, \mathrm{SD}=.71)$ leader BI conditions; thus providing support for H1a. Results for organizational identification also indicated a significant difference $(F(2)=36.5, p<.001, \eta 2=.42)$ between high $(M=4.11, \mathrm{SD}=.68)$, low $(M=2.54$, $\mathrm{SD}=1.05)$, and neutral $(M=3.92, \mathrm{SD}=.72)$ organizational BI conditions; thus providing support for $\mathrm{H} 1 \mathrm{~b}$.

\section{Study 2}

Study 2 examines the effects of leader BI and organizational BI on follower BI and the mediating role of identification in these relationships. It also aims to replicate Study 1 findings regarding the causal relationship between $\mathrm{BI}$ and follower identification.

According to Simons' (2002) theory, BI is a subjective concept as it is in the eye of beholder. Therefore, to accurately understand the impacts of leader BI and organizational BI, it is prudent to examine the behaviors of the individuals who observe them (Davis and Rothstein 2006). Surprisingly, there are relatively few studies that examine follower behaviors with regard to leader and organizational BI (Davis and Rothstein 2006; Simons et al. 2015). Drawing on Bandura's (1977) social learning theory that suggests followers are observing and imitating the salient behaviors of their influential others, we examine the role of leader and organizational BI in shaping follower BI. Although follower BI is a relatively neglected research area, limited prior research has shown that follower BI is an important determinant of follower performance (Dirks and Skarlicki 2009; Palanski and Yammarino 2011) as well as trust (Palanski and Yammarino 2011). Given this conceptual and empirical support, we believe it is important to examine follower BI. Moreover, by utilizing a social identity perspective that emphasizes the importance of follower identification as a channel through which organizational actors influence members (Pratt 1998; Kark et al. 2003), we also propose that the effects of leader and organizational BI on follower BI will be more powerful through the mediation of follower identification processes.

\section{Leader Behavioral Integrity and Follower Behavioral Integrity}

Social learning theory (Bandura 1977) suggests that individuals learn moral values, beliefs, and prosocial behaviors from the attributes they observe in their role models. When these learnings are considered important, they are emulated and adopted by individuals. On the one hand, individuals select their role models by focusing on the credibility, prestige, and trustworthiness of the person (Bandura 1977). Leader BI provides credibility and reliability to leader in the eye of followers (Simons 2002; Holmes and Parker 2017). In addition, leader BI facilitates the role-modeling process as leaders with BI not only talk about their values, but also genuinely exhibit these values in their actions and thus truly lead by example. Therefore, it is very likely for followers to see their leader with BI as role model. On the other hand, followers are modeling the salient and valued characteristics from their leader (Bandura 1997). Especially, when followers perceive their leader as an ethical role model, they are more likely to engage in ethical behaviors as modeled by the leader (Bandura 1977) because ethical leaders' attractive characteristics are important source for observation and emulation for them (Brown et al. 2005; Walumbwa and Schaubroeck 2009). Since leader BI is an important aspect of ethical behaviors in an organization (Palanski and Yammarino 2007), we assume that followers will adopt BI from their leaders through the role-modeling process. To the best of our knowledge, Palanski and Yammarino (2011) conducted the only study that has empirically tested and found a positive relationship between leader BI and follower BI. Thus:

H2a Leader BI will have a positive relationship with follower BI.

\section{Organizational Behavioral Integrity and Follower Behavioral Integrity}

It has been argued that organization as an entity is a social actor and has its own characteristics that influence its individual members (Shore and Coyle-Shapiro 2003). Prior research has utilized social learning theory (Bandura 1977) to suggest that organizational characteristics, 
such as organizations' structure, culture, information systems, norms, and values, can influence its members on the basis of social learning (Harrison and Mclntosh 1992). Employee-organization relationship literature has also shown that organizations significantly influence employees' attitudes and behaviors (Riketta and van Dick 2005; Alcover et al. 2017).

According to Simons (2002) organizations with BI do as they say in a clear and transparent way, putting their corporate strategies, norms, and values into practice. Moreover, an organization with BI keeps its explicit or implicit promises to its members (Simons 2002). When employees perceive BI-related organizational practices as appropriate and pleasing, the social learning context of the organization may cause them to associate with and emulate these practices in the form of follower BI. Organizational BI may also influence followers' BI by setting and supporting organizational shared norms and culture that require BI. Organizations often use communication codes and policies to encourage members to act upon organizational values and norms (Harrison and Mclntosh 1992). While these codes and policies only tell members how they should behave, an organization with BI also acts upon them; thus, BI amplifies these norms for members, making them more salient to recognize and adopt. In that case, it is likely that organizational BI facilitates an organizational culture that encourages follower BI. Prior research has also shown organizational culture is highly effective in influencing employees' ethical behaviors (Cameron et al. 2004; Trevino et al. 1998). Taken together, we advance the following hypothesis:

H2b Organizational BI will have a positive relationship with follower BI.

\section{The Mediating Role of Follower Identifications}

According to the social identity perspective, once followers identify with a leader, their self-concept is likely to be affected by the leader's beliefs, values and attitudes, leading followers to align their behavior to that of the leader (Kark et al. 2003; Ashforth et al. 2015). Also, in social learning theory, personal identification is considered to be one of the main mechanisms that facilitates the role-modeling process. According to Bandura (1969), identification is a process "in which a person patterns his thoughts, feelings, and actions after another person who serves as a model" (p. 214). In this sense, leader identification serves as the mechanism through which that leader, as the role model, influences followers so that they internalize and adopt the role model's behaviors (Ashforth et al. 2015).

Prior studies have supported the mediating role of leader identification in the relationship between leader behaviors and follower behavioral outcomes (e.g., Kark et al. 2003; De
Cremer and van Knippenberg 2005). Most notably, empirical research provides evidence that followers with higher leader identification are more likely to adopt leader's ethics into their own self-concepts (Wang et al. 2019). Palanski and Yammarino (2011) found a positive but modest $(b=.25$, $p<.05)$ connection between leader BI and follower BI and called for future studies to find possible mediators so that we can understand this relationship better. Answering this call, we argue that leader identification can be a mechanism that explains the relationship between the BI of leaders and followers. Thus:

H3a Leader identification will mediate the positive relationship between leader BI and follower BI.

As we have previously described, organizational identification takes place when individuals are attracted to and then accept the attributes of the organization as their own (Sluss and Ashforth 2007). In this sense, one of the main consequences of organizational identification is encouraging members to align their behaviors with organizational values and behaviors (Pratt 1998; Kark et al. 2003). Previous research has suggested that employees' organizational identification increases extra-role behaviors, enhances job performance, and decreases counterproductive work behaviors toward the organization (Lee et al. 2015). Following this research, we expect that when employees perceive their organization to be acting with BI, they will be more likely to identify with the organizational collective and place a high value on their membership therein. They will thus be more likely to act with consistency and keep their promises in an effort to maintain their positive self-image and valued organizational membership. Thus, we argue that organizational identification will be an important mediating mechanism explaining the effect of organizational BI on follower BI.

H3b Organizational identification will mediate the positive relationship between organizational BI and follower BI.

\section{Method}

\section{Participants and Procedures}

Data were collected from 200 United States full-time working professionals via Prolific. Participants received a small cash payment. The participants ranged in age from 20 to $73(M=37) ; 57 \%$ were male; $63.5 \%$ had a college degree, $18.5 \%$ were high school graduates, $15 \%$ had master's degrees, $1 \%$ had doctoral degrees, $1.5 \%$ had professional degrees, and $0.5 \%$ did not complete high school. They had a position of tenure on average of 6.8 years. The participants were working in the private sector $(66.2 \%)$ or public 
organizations (33.3\%) and held nonmanagerial (56\%) or managerial positions (44\%).

In order to provide evidence that leader and organizational BI predict followers' BI and identification mediates these relationships, as in Study 1, we used the same online experimental design, manipulating the actions and behaviors of an imaginary leader and organization in written scenarios. For leader BI, participants were randomly assigned to one of two scenarios; either to a high $(N=48)$ or a low $(N=45)$ leader BI condition. Similarly, for organizational BI, participants were randomly assigned to one of two scenarios; either to a high $(N=51)$ or a low $(N=51)$ organizational BI condition. For the rest, we applied the same procedure as described under Study 1.

\section{Measures}

For consistency across studies, we used the same scales from study 1 for manipulation checks, leader and organizational BI ( $\alpha=.99$ and $\alpha=.99$, respectively) and for dependent variables, leader and organizational identification $(\alpha=.87$ and $\alpha=.90$, respectively). To measure follower BI as a dependent variable, we adapted the eight-item behavioral integrity scale developed by Simons et al. (2007) $(\alpha=.97)$. The scale was modified slightly to reflect the name of the leader or organization in the scenarios. A sample follower BI item for leader BI conditions is "If Alex were my manager, there would be a match between my words and actions" and a follower $\mathrm{BI}$ item for organizational $\mathrm{BI}$ conditions is "If $\mathrm{ABC}$ were my organization, there would be a match between my words and actions." Since the participants rated their own $\mathrm{BI}$ and prior research has identified BI as a normative ideal of desirable organizational behaviors (Palanski and Yammarino 2009), we measured and controlled for respondents' moral identity (symbolization $[\alpha=.87]$ and internalization $[\alpha=.78])$ (Aquino and Reed 2002) and sincerity ( $\alpha=.85$ ), a dimension of the honesty-humility scale based on HEXACO-60 assessment (Ashton and Lee 2009). All items for the measures were rated based on a five-point Likert scale ranging from 1 (strongly disagree) to 5 (strongly agree).

\section{Results}

First, results from the ANOVA show that the manipulations were valid for leader BI $(F(1)=1638.6, p<.001, \eta 2=.94)$; thus, demonstrating a difference between high $(M=4.8$, $\mathrm{SD}=.32)$ and low $(M=1.3, \mathrm{SD}=.50)$ conditions and organizational BI $(F(1)=86.4, p<.001, \eta 2=.89)$, thus demonstrating a difference between high $(M=4.79, \mathrm{SD}=.42)$ and low $(M=1.28, \mathrm{SD}=.74)$ conditions. Second, we conducted ANOVA to test if data replicate Study 1 results regarding $\mathrm{H} 1 \mathrm{a}$ and H1b. Results for leader identification indicated
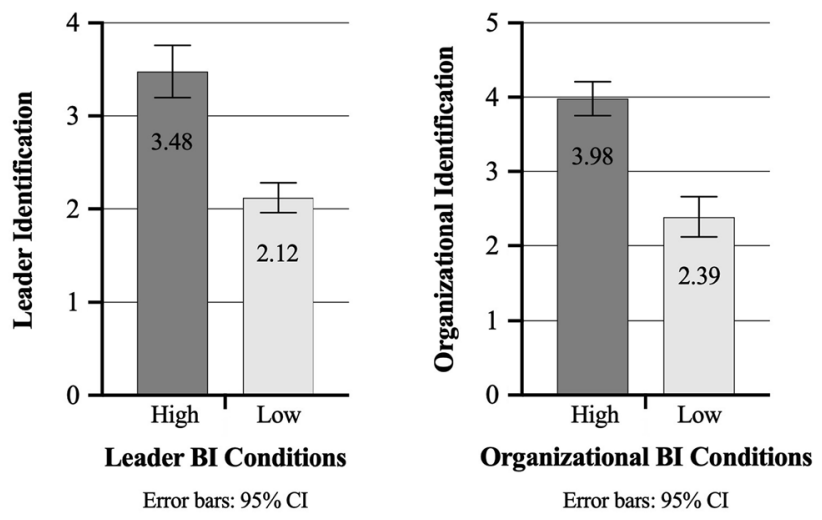

Fig. 2 Mean comparisons for behavioral integrity manipulation conditions and follower identifications in Study 2
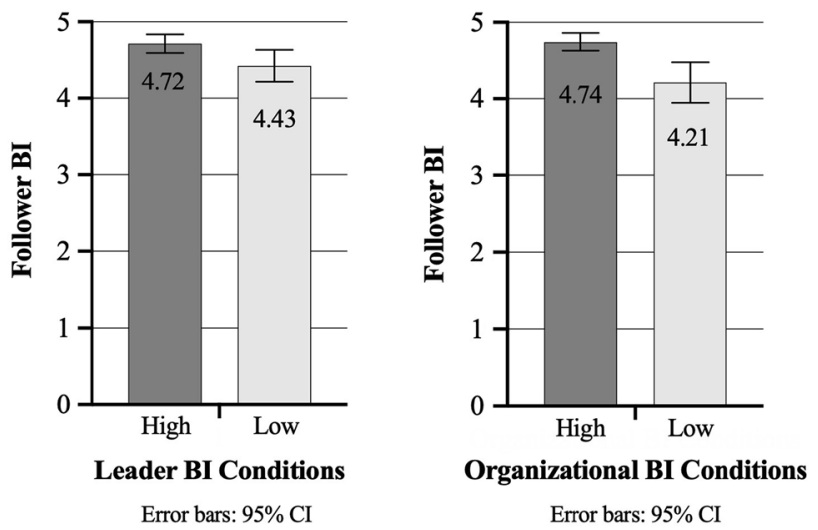

Fig. 3 Mean comparisons for behavioral integrity manipulation conditions and follower BI in Study 2

a significant difference $(F(1)=68.9, p<.001, \eta 2=.43)$ between high $(M=3.48, \mathrm{SD}=.96)$ and low $(M=2.12$, $\mathrm{SD}=.53$ ) leader $\mathrm{BI}$ conditions. Results for organizational identification also indicated a significant difference $(F(1)=8.8, p<.001, \eta 2=.44)$ between high $(M=3.98$, $\mathrm{SD}=.80)$ and low $(M=2.39, \mathrm{SD}=.97)$ organizational $\mathrm{BI}$ conditions. Thus, similar to Study 1, H1a and H1b were supported. Figure 2 shows the mean comparisons for leader and organizational BI manipulation conditions with follower identifications.

Third, we conducted ANOVA to see if there is a difference in follower BI between high and low leader and organizational BI conditions, respectively. For leader BI, results indicated a significant difference in follower BI $(F(1)=6.04, \mathrm{p}=.016, \eta 2=.06)$ between high $(M=4.72$, $\mathrm{SD}=.41)$ and low $(M=4.43, \mathrm{SD}=.58)$ leader $\mathrm{BI}$ conditions. Also, results indicated a significant difference in follower BI $(F(1)=13.52, p<.001, \eta 2=.12)$ between high $(M=4.74$, $\mathrm{SD}=.41)$ and low $(M=4.21, \mathrm{SD}=.92)$ organizational $\mathrm{BI}$ conditions. Thus, $\mathrm{H} 2 \mathrm{a}$ and $\mathrm{H} 2 \mathrm{~b}$ were supported. Figure 3 
shows the mean comparisons for leader and organizational BI manipulation conditions with follower BI.

Finally, to test the mediating roles of leader identification between leader BI and follower BI (H3a), and organizational identification between organization $\mathrm{BI}$ and follower BI (H3b), we used the PROCESS macro (Hayes 2016), applied a 1,000-bootstrap resampling method to estimate the specific indirect effects. Mediation is supported when the range between the lower and upper bootstrapped 95\% $\mathrm{CI}$ around the indirect effect does not contain zero (Preacher and Hayes 2008). The indirect effect of leader BI on follower BI via leader identification failed to reach significance, as zero fell in the $95 \%$ confidence interval, thus, H3a was not supported. Results revealed a significant positive indirect effect of organization BI on follower BI via organizational identification $(b=.26, \mathrm{SE}=.09,95 \%$ confidence interval (CI) $[.06, .43])$; thus, H3b was supported.

\section{Study 3}

Study 3 is an extension of Studies 1 and 2 and aims to address the role of BI in followers' OCB and test all hypothesized relationships with multisource field data.

OCB has received significant attention from researchers as a form of extra-role behaviors (Lee and Allen 2002). OCB reflects employees' discretionary behaviors that are beyond their formal job descriptions and contribute to the maintenance and enhancement of the social and psychological context that facilitates overall organizational functioning and effectiveness (Organ 1997). We focus on organizational citizenship behaviors toward organizations (OCBO) including adhering to organizational rules and complying with the organizations' norms and values, thus benefitting the organization as a whole (Williams and Anderson 1991). Simons' (2002) theory asserts that BI ensures communication clarity that determines the norms among followers regarding appropriate workplace behaviors, which in turn enhances followers' OCBs. Following this theoretical work, we examine the relationships between leader and organizational BI and followers' OCBO.

\section{Behavioral Integrity and Organizational Citizenship Behaviors}

Behavioral integrity theory (Simons 2002) argues that when $\mathrm{BI}$ is low, it is very likely for employees to experience uncertainty regarding the norms of desirable work behaviors with a detrimental effect on extra-role behaviors. On the other hand, when BI is high, the leader and organization will consistently follow through on values and commitments, thus they will send clear signals to followers about desired and undesired work behaviors (Simons 2002; Simons et al. 2015). In that case, followers will clearly understand what is expected of them and in turn, it will be easier to meet those expectations by engaging in desirable extra-role behaviors such as OCBO.

Reviews of the leadership literature suggest that when ethical leaders are consistent in their expectations of employees and act upon the normatively appropriate work behaviors, employees adopt more extra-role behaviors (Brown et al. 2005; Mayer et al. 2009). It is mainly because leaders are exemplifying the organization norms by showing their commitment to the organizational goals (Dust et al. 2014) and because the social learning context facilitates the process of role-modeling that followers are likely to emulate the behaviors that leaders exemplify (Yaffe and Kark 2011). When leaders are consistent in demonstrating these behaviors, their BI becomes more salient to followers. Accordingly, we can assume that the more followers perceive their leader to be high in BI, the more they recognize the leader's influence as a role model of prosocial behaviors. Thus:

H4a Leader BI will have a positive relationship with follower OCBO.

Regarding the organizational BI-follower OCBO relationship, we build on Bandura's (1977) social learning theory arguments about the role of organizational context in influencing members' performance. Social learning theory suggests that when an organization is perceived by members as salient or potent in its values, behaviors, and norms, its members enhance their efficacy expectations regarding behaviors that are consistent with the perceived norms or pressures of the organization (Harrison and Mclntosh 1992). Furthermore, BI provides communication clarity that augments the organization's norms and values in the eyes of its members (Vogelgesang et al. 2013). Thus, it is likely that organizational BI will help align follower prosocial behaviors with what the organization has emphasized. Moreover, according to the social learning perspective, members tend to increase their performance to meet organizational expectations because they think conformity will enhance their chances for acceptance by the organization (Harrison and Mclntosh 1992). Organizational BI reduces role ambiguity for members as it clarifies the organization's expectations in terms of performance and appropriate work behaviors. Therefore, we advance the following hypothesis:

H4b Organizational BI will have a positive relationship with follower OCBO.

\section{The Mediating Role of Follower Identifications}

Simons (2002) had proposed that BI is likely to predict follower prosocial behaviors directly (as explained above) or through its impact on followers' attitudes. Based on Simons' 
(2002) theory and research on follower identification that has shown that identification with leader and with organization enhance follower OCB (e.g., Marstand et al. 2020; Zhang and Chen 2013), we examine leader identification and organizational identification as mediating mechanisms in leader and organizational BI and follower OCBO relationships.

By identifying with their leaders, followers view the interests of their leader as their own and are more likely to internalize the performance standards and norms that are specified by the leader (Sluss and Ashforth 2007). In this sense, leader identification motivates followers to work toward the supervisor's work agenda by engaging in citizenship behaviors. Prior research has also supported the mediating role of leader identification in the relationship between leader behaviors and follower OCB (e.g., Zhang and Chen 2013). In sum, we argue that employees who identify with a leader who acts with BI will be more likely to engage in extra-role behaviors that are valued by the leader and the organization. Thus, we expect leader BI to influence follower OCBO through leader identification:

H5a Leader identification will mediate the positive relationship between leader BI and follower OCBO.

Based on the sense of ownership employees experience through organizational identification, they internalize the organization's values and goals and act in the best interest of the organization by exhibiting positive extra-role behaviors (Smidts et al. 2001). Moreover, organizational identification leads to a sense of ownership that motivates followers to contribute to the good of the organization (Smidts et al. 2001). Lee et al. (2015) have found strong meta-analytic support for the link between organizational identification and follower OCBO across multiple independent studies. Therefore, we suggest that organizational BI can foster a positive influence on follower extra-role behaviors toward the organization trough organizational identification.

Several studies have shown the mediating role of organizational identification between organizational-level constructs and members' outcomes. For example, Restubog et al. (2008) showed that organizations' failure to keep their promises to employees reduces employees' identification with the organization and conversely decreases their willingness to engage in OCB because they lose the pride in their organizational membership. Miao and Zhou (2020) demonstrated that employees' perception of organizational inconsistency in words and deeds restricts members' organizational identification and when identification with organization is hurt, members tend to believe the organization no longer deserves belongingness; thus, they engage in more counterproductive work behaviors toward the organization. Although these studies did not directly measure organization $\mathrm{BI}$, we believe it is very likely that organizational BI can positively influence follower extra-role behaviors toward the organization through organizational identification. In sum, relying on social identity theory and organizational identification literature, we argue that organizational identification can act as an important mechanism to explain the relationship between organizational BI and follower OCBO. Therefore, we hypothesized the following:

H5b Organizational identification will mediate the positive relationship between organizational $\mathrm{BI}$ and follower OCBO.

\section{Method}

\section{Sample and Procedure}

For study 3, questionnaires were administered to 559 firefighters and nonoperational staff at a Fire and Rescue Service in the United Kingdom. The data were collected from two sources, followers and co-workers. In the follower's survey, firefighters and staff rated their perceptions of their leaders and organization's BIs, as well as the extent to which they identify with their leader and with their organization. The co-worker survey included another source measurement in the form of a co-worker questionnaire and participants were asked to hand the co-worker questionnaire to one of their colleagues. These co-workers rated the focal participants' $\mathrm{BI}$ (follower BI) and OCBO (follower OCBO). Respondents anonymously completed the paper and pencil questionnaires, enclosed them in pre-addressed envelopes, and posted them directly back to the research team.

A total of 282 completed surveys were obtained, with a response rate of $54 \%$. Of the 282 respondents, $78.4 \%$ were male; $20.7 \%$ were aged between 18 and 34 years old $26.6 \%$ were $35-44$ years old, and $46.2 \%$ were above 45 years old. The participants were in operational roles (78\%) or nonoperational roles $(17.7 \%)$ and a majority $(80.3 \%)$ of them had been working in the Fire and Rescue Service for more than 5 years.

\section{Measures}

\section{Behavioral Integrity}

Leader, organizational, and follower BI were measured using an eight-item scale adapted from Simons et al.'s (2007) behavioral integrity scale $(\alpha=.96, .97$, and .95, respectively). For leader BI and organizational BI, participants rated their perceptions of their immediate leader and organization in the follower survey. Follower BI was measured as a co-worker rating so that each co-worker rated the focal worker's BI in the co-worker survey. A sample item for follower BI is "My co-worker delivers on promises." All 
items for these measures (as well as all other measures in this study) were rated on a seven-point scale ranging from 1 ("strongly disagree") to 7 ("strongly agree"). Although there is sufficient theoretical support for examining leader $\mathrm{BI}$ and organizational BI as separate constructs, organizational BI measure has not been used yet. Therefore, we conducted a confirmatory factor analysis to assess if leader BI and organizational BI are indeed different constructs. First, we specified a one-factor model which specified the leader BI and organizational BI items loaded on the same single factor. For the second confirmatory model, we specified a two-factor model that specified the leader BI items loaded on one factor and organizational BI items loaded on another factor. Then, we compared the goodness-of-fit of these two rival models. The model comparison showed that the twofactor model provided a better fit for the data $\left(\chi^{2}(\mathrm{df})=76.53\right.$ (19), $\mathrm{CFI}=.98, \mathrm{TLI}=.97, \mathrm{RMSEA}=.10, \mathrm{SRMR}=.01)$ than the one-factor model $\left(\chi^{2}(\mathrm{df})=1603.59(20), \mathrm{CFI}=.53\right.$, $\mathrm{TLI}=.35, \mathrm{RMSEA}=.51, \mathrm{SRMR}=.31)(\Delta \chi 2=1527,06$, $\Delta \mathrm{df}=1, p<.001)$. Thus, this finding provides statistical support for the distinctiveness of organizational BI and leader BI.

\section{Leader Identification}

Leader identification was measured with a five-item scale developed by Mael and Tetrick (1992). A sample item is "My manager's successes are my successes" $(\alpha=.87)$.

\section{Organizational Identification}

Organizational identification was measured with a threeitem scale adapted from Smidts et al. (2001). The three items are as follows: "I feel strong ties with my organization," "I experience a strong sense of belonging to my organization," and "I feel proud to work for my organization" $(\alpha=.90)$.

\section{OCBO}

Followers' extra-role behaviors toward the organization were measured with an eight-item scale adapted from Lee and Allen (2002). We asked co-workers to rate the focal workers' OCBO in the co-worker survey. A sample item is "He/ she offers ideas to improve the functioning of the service" $(\alpha=.89)$.

\section{Control Variables}

We controlled for organizational tenure (in years) based on the theoretical tenets of social learning theory (Bandura 1971) suggesting that individuals must have the opportunity to perceive the behavior of an influential other as a precondition for the social learning process. Employees with a low tenure may have less opportunities to recognize BI of their leader and organization and may lack key knowledge about the target that is needed to facilitate and develop identification (Kark et al. 2003) as well as extra-role behaviors (Organ and Ryan 1995). Tenure with the organization has been also found to affect employee identification (e.g., Ashforth et al. 2015) and OCB (e.g., Kacmar et al. 2011). Furthermore, we tested several demographic variables including age, gender, and role as they have been found to influence our key variables (e.g., Tsiu and O'Reilly 1989; Organ and Ryan 1995). Correlation analyses indicated that age and gender were not significantly associated with key variables; thus, we excluded them from hypotheses testing to preserve statistical power (Becker 2005). Employee role (1= operational; $2=$ nonoperational) was significantly correlated with variables of interest. Given that job position has been found to play a role in influencing employees' attitudes and behaviors in an organization (Jung and Yoon 2012), it was included as a control variable in subsequent analyses.

\section{Results}

\section{Preliminary Analyses}

Table 1 presents means, standard deviations, correlations, and reliabilities of the study variables. We then tested the measurement model using confirmatory factor analyses (CFA) to establish the construct distinctiveness of the variables used in the study. Due to the limited sample size, we were not able to perform a complete item-level CFA; instead, we assessed a partially disaggregated measurement model using parcels of items based on prior research suggestions (Hall et al. 1999). As the parcel-building method, we used the factorial algorithm (Rogers and Schmitt 2004). Using the factorial algorithm as parcel-building method (Rogers and Schmitt 2004), we first conducted a factor analysis for each measure and then created parcels based on the computed factor loadings. For each parcel sequentially, we took the item with the highest to the lowest factor loadings. Following this method, we created parcels that each contains two items for all measurements in the study. Eventually, the measurement model comparisons indicate that the six-factor model provide a superior model fit to the data $(\chi 2(\mathrm{df})=360.70$ (194), CFI $=.97, \mathrm{RMSEA}=.07, \mathrm{SRMR}=.03$ ) than all other alternative models (see Table 2). Thus, the 6-factor model yielded an acceptable fit to the data and provided support for the distinctiveness of our key constructs.

\section{Hypotheses Testing}

We tested our study hypotheses using regression analyses and PROCESS macro. To increase confidence in the unique 
Table 1 Means, standard deviations, correlations, and alphas of variables for Study 3

\begin{tabular}{lllllllllll}
\hline Variables & $M$ & SD & 1 & 2 & 3 & 4 & 5 & 6 & 7 & 8 \\
\hline 1. Role & 1.19 & .39 & & & & & & & \\
2. Tenure & 2.76 & 1.09 & $-.25^{* *}$ & & & & & & \\
3. Leader BI & 5.46 & 1.12 & .02 & $-.24^{* *}$ & $(.97)$ & & & & \\
4. Organizational BI & 4.28 & 1.53 & $.22^{* *}$ & $-.2^{* *}$ & $.22^{* *}$ & $(.97)$ & & & \\
5. Leader identification & 4.13 & 1.31 & -.02 & $-.13^{*}$ & $.47^{* *}$ & $.23^{* *}(.87)$ & & \\
6. Organizational identification & 5.32 & 1.43 & $.22^{* *}$ & $-.25^{* *}$ & $.19^{* *}$ & $.70^{* *}$ & $.26^{* *}$ & $(.90)$ & & \\
7. Follower BI & 6.04 & .78 & .03 & .007 & $.17^{* *}-.01$ & .11 & .08 & $(.96)$ \\
8. Follower OCBO & 5.77 & .87 & .08 & -.02 & $.17^{* *}$ & $.34^{* *}$ & $.17^{* *}$ & $.39^{* *}$ & $.66^{* *}(.89)$
\end{tabular}

Note. $N=280$. Values in parentheses along the diagonal are Cronbach's alphas. Role was coded as 1 operational and 2 nonoperational. Tenure was coded as $1=0-5$ years, $2=6-9$ years, $310-19$ years, $4=20$ years and above, $B I$ behavioral integrity, $O C B O$ organizational citizenship behavior toward organization

$* p<.05, * * p<.01$
Table 2 Results of measurement model comparisons for Study 3

\begin{tabular}{lllllll}
\hline Models & $\chi^{2}(d f)$ & CFI & TLI & RMSEA & SRMR & $\Delta \chi^{2} /(\Delta d f)$ \\
\hline $\begin{array}{l}\text { 6-factor (Hypoth- } \\
\text { esized Model) }\end{array}$ & $360.70(194)$ & .98 & .97 & .05 & .04 & - \\
5-factor A & $2083.88(199)$ & .73 & .69 & .18 & .18 & $344.63(5)^{* *}$ \\
5-factor B & $1740.82(199)$ & .78 & .74 & .15 & .17 & $276.02(5)^{* *}$ \\
5-factor C & $840.97(199)$ & .91 & .89 & .10 & .10 & $96.05(5)^{* *}$ \\
4-factor & $2563.63(203)$ & .66 & .61 & .19 & .21 & $244.77(9)^{* *}$ \\
3-factor & $3929.93(206)$ & .47 & .40 & .24 & .26 & $297.43(12)^{* *}$ \\
2-factor & $4373.06(208)$ & .40 & .34 & .25 & .24 & $286.59(14)^{* *}$ \\
1-factor & $4959.55(209)$ & .32 & .25 & .27 & .26 & $306.59(15)^{* *}$ \\
\hline
\end{tabular}

Note. 5- factor Model A: this model combines leader behavioral integrity (BI) and organization BI as one factor; 5- factor Model B: this model combines leader BI and follower BI as one factor; 5- factor Model C: this model combines leader identification and organizational identification as one factor; 4- factor Model: this model combines leader BI, organization BI, and follower BI as one factor; 3-factor Model: this model combines leader BI, organization BI, and follower BI as one factor, leader identification and organizational identification as another factor; 2-factor Model: this model combines leader BI, organization BI, follower $\mathrm{BI}$, leader identification, and organizational identification as one factor; 1-factor Model combines all items. The chi-square difference for each model reflects its deviation from the 6-factor model

$* * p<.01$ contribution of each independent variable (i.e., leader BI or organizational BI) on mediators and dependent variables, in all our hypotheses testing (i.e., direct effects and mediation models), we controlled for the effect of the other independent BI variable. For example, while estimating the effect of organizational BI on dependent variables, along with other control variables (i.e., role and tenure), we also controlled for the effect of leader BI.

Table 3 presents regression results for hypotheses related to leader BI and dependent variables (H1a, H2a, and H4a). As can be seen in Table 3, leader BI significantly predicted leader identification $(B=.51, p<.001)$ as well as follower BI $(B=.14, p<.01)$. Thus, similarly to Studies 1 and 2 , the data supported $\mathrm{H} 1 \mathrm{a}$ and $\mathrm{H} 2 \mathrm{a}$. In addition, there was a significant positive relationship between leader BI and follower OCBO $(B=.10, p<.01)$; thus, H4a was also supported. Table 4 presents the regression results for hypotheses related to organizational BI and dependent variables $(\mathrm{H} 1 \mathrm{~b}, \mathrm{H} 2 \mathrm{~b}$, and $\mathrm{H} 4 \mathrm{~b})$. There was a significant positive relationship between organizational $\mathrm{BI}$ and organizational identification $(B=.61$, $p<.001)$, thus once again H1b was supported. However, the results did not provide support for the direct effect of organizational BI on follower BI $(B=-.02$, ns). Thus, $\mathrm{H} 2 \mathrm{~b}$ was not supported and the Study 2 results with regard to this hypothesis were not replicated in Study 3. Finally, there was a significant positive relationship between organizational BI and follower OCBO $(B=.18, p<.001)$, supporting H4b.

To test the indirect effects in our model proposed by $\mathrm{H} 3 \mathrm{a}, \mathrm{H} 3 \mathrm{~b}, \mathrm{H} 5 \mathrm{a}$ and H5b, we used the PROCESS macro and applied a 1,000-bootstrap resampling method to estimate the standard errors of the specific indirect effects. Leader BI did not show a significant indirect effect on follower BI $(b=.02$, 
Table 3 Regression analysis result for leader behavioral integrity and outcomes in Study 3

\begin{tabular}{|c|c|c|c|c|c|c|c|c|}
\hline \multirow[t]{2}{*}{ Predictors } & \multicolumn{2}{|c|}{ Leader identification } & \multicolumn{3}{|l|}{ Follower BI } & \multicolumn{3}{|c|}{ Follower OCBO } \\
\hline & Step1 & Step2 & Step1 & Step2 & Step3 & Step1 & Step2 & Step3 \\
\hline Constant & $4.01(.41)^{* * *}$ & $1.07(.52)^{*}$ & $5.96(.25)^{* * *}$ & $5.18(.35)^{* * *}$ & $5.15(.35)^{* * *}$ & $4.75(.27)^{* * *}$ & $4.24(.37)^{* * *}$ & $4.18(.38)^{* * *}$ \\
\hline \multicolumn{9}{|l|}{ Control } \\
\hline Role & $.33(.20)$ & $-.22(.18)$ & $.07(.12)$ & $.1(.12)$ & $.1(.12)$ & $.05(.13)$ & $.07(.13)$ & $.08(.13)$ \\
\hline Tenure & $-.13(.07)$ & $-.01(.07)$ & $.01(.04)$ & $.04(.04)$ & $.04(.04)$ & $.04(.05)$ & $.06(.05)$ & $.06(.05)$ \\
\hline Organization BI & $.20(.05)^{* * *}$ & $.13(.05)^{* *}$ & $-.01(.03)$ & $-.2(.03)$ & $-.03(.03)$ & $.19(.03)^{* * * *}$ & $.18(.03)^{* * *}$ & $.17(.03) * * *$ \\
\hline \multicolumn{9}{|l|}{ Main effect } \\
\hline Leader BI & & $.51(.06)^{* * *}$ & & $.14(.04)^{* *}$ & $.12(.05)^{*}$ & & $.10(.05)^{*}$ & $.06(.05)$ \\
\hline Mediator & & & & & & & & \\
\hline Leader Identification & & & & & $.03(.04)$ & & & $.05(.04)$ \\
\hline $\mathrm{R} 2$ & .07 & .24 & .001 & .04 & .04 & .12 & .13 & .13 \\
\hline R2 change & & .17 & & .04 & .002 & & .01 & .004 \\
\hline
\end{tabular}

Note $N=280$, Standard errors are given in parentheses. $B I$ behavioral integrity, $O C B O=$ organizational citizenship behavior toward organization ${ }^{*} p<.05, * * p<.01, * * * p<.001$

Table 4 Regression analysis result for organizational behavioral integrity and outcomes in Study 3

\begin{tabular}{|c|c|c|c|c|c|c|c|c|}
\hline \multirow[t]{2}{*}{ Predictors } & \multicolumn{2}{|c|}{ Organizational Identification } & \multicolumn{3}{|l|}{ Follower BI } & \multicolumn{3}{|c|}{ Follower OCBO } \\
\hline & Step1 & Step2 & Step1 & Step2 & Step3 & Step1 & Step2 & Step3 \\
\hline Constant & $4.17(.50)^{* * *}$ & $2.65(.46)^{* * *}$ & $5.12(.34)^{* * *}$ & $5.18(.35)^{* * *}$ & $4.95(.37)^{* * *}$ & $4.70(.38)^{* * *}$ & $4.23(.37)^{* * *}$ & $3.73(.38)^{* * *}$ \\
\hline \multicolumn{9}{|l|}{ Control } \\
\hline Role & $.65(.21)^{* *}$ & $.23(.16)$ & $.08(.12)$ & $.10(.12)$ & $.08(.12)$ & $.19(.13)$ & $.06(.13)$ & $.02(.12)$ \\
\hline Tenure & $-.23(.08)^{* *}$ & $-.14(.06)^{*}$ & $.04(.04)$ & $.04(.04)$ & $.05(.04)$ & $.03(.05)$ & $.06(.05)$ & $.10(.05)$ \\
\hline Leader BI & $.19(.07)^{*}$ & $.03(.06)$ & $.13(.04)^{* *}$ & $.14(.04)^{* *}$ & $.13(04)^{* *}$ & $.14(.05)^{* *}$ & $.10(.05)^{*}$ & $.08(.04)$ \\
\hline \multicolumn{9}{|l|}{ Main effect } \\
\hline Organizational BI & & $.61(.04)^{* * *}$ & & $-.02(.03)$ & $-.08(.04)$ & & $.18(.03)^{* * *}$ & $.06(.04)$ \\
\hline \multicolumn{9}{|l|}{ Mediator } \\
\hline $\begin{array}{r}\text { Organizational } \\
\text { identification }\end{array}$ & & & & & $.09(.04)^{*}$ & & & $.20(.05)^{* * *}$ \\
\hline $\mathrm{R} 2$ & .11 & .50 & .03 & .04 & .05 & .04 & .13 & .18 \\
\hline $\mathrm{R} 2$ change & & .39 & & .002 & .01 & & .10 & .05 \\
\hline
\end{tabular}

Note. $N$ 280, Standard errors are given in parentheses. BI behavioral integrity, $O C B O$ organizational citizenship behavior toward organization. $* p<.05, * * p<.01, * * * p<.001$

$\mathrm{SE}=.03,95 \%$ confidence interval $(\mathrm{CI})[-.03, .08])$ as well as follower OCBO $(b=.03, \mathrm{SE}=.03,95 \%$ confidence interval (CI) $[-.03, .09])$ via leader identification, respectively; thus, data did not support H3a (similar to Study 2) and H5a. On the other hand, organizational BI was found to have a significant indirect effect on follower $\mathrm{BI}(b=.11, \mathrm{SE}=.05$, $95 \%$ confidence interval (CI) $[.01, .21])$ via organizational

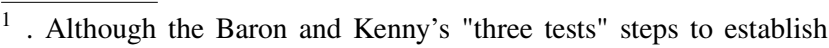
mediation do not hold given the nonsignificant direct effect, newer approaches to mediation argue for these steps to be replaced with one and only one test; the bootstrap test of the indirect effect $\mathrm{a} x \mathrm{~b}$ (see Zhao et al. 2010).
}

identification. This significant mediation effect was consistent with our Study 2 results; thus, H3b was supported. ${ }^{1}$ Finally, organizational BI showed a significant indirect effect on follower OCBO $(b=.21, \mathrm{SE}=.06,95 \%$ confidence interval (CI) $[.10, .32])$ via organizational identification, thus, H5b also supported.

\section{General Discussion}

The present research advances behavioral integrity theory, and contributes to the integrity and ethical leadership literatures. Our experimental studies (Studies 1 and 2) showed that followers identify more strongly with the leader and 
the organization when leader BI and organizational BI were high, respectively. Our multisource field study (Study 3) also replicated these findings, illustrating a positive significant relationship between leader and organizational BI and followers' identifications. Regarding leader BI and follower outcomes, both our experimental (Study 2) and our field study (Study 3) showed positive direct effects of leader BI and organizational BI on follower BI. We further found a direct positive relationship between leader and organizational BI and follower OCBO in our field study. With regards to mediation, our results did not provide support for the mediating role of leader identification in the relationship between leader BI and follower outcomes. Nonetheless, we found strong support for the mediating role of organizational identification in the relationship between organizational BI and follower outcomes.

\section{Theoretical Contributions}

Our findings from the three studies make several key contributions to the management and integrity literatures. For the first time in the literature, BI was examined from three different foci: leader, organization and follower. One of the most important contributions of the present research is that it provided initial empirical support for the prior theoretical claims (e.g., Simons 2002; Palanski and Yammarino 2009) that the construct of $\mathrm{BI}$ is not exclusive to the leaders, but it could apply to other organizational entities such as the organizations and the followers. While previous empirical studies relied only on leader BI as a key predictor of follower desirable outcomes, the present study extends this literature by examining the separate effects of leader BI and organizational BI on followers' attitudes and behaviors that are important for the organization. Thus, our study clarifies the role of different BI referents and finds that they are both important in determining follower outcomes. Particularly, our findings showed that when leaders and organizations keep promises and take actions aligned with stated intentions, employees identify more strongly with the leader and the organization. Moreover, leader and organizational BI play important roles in shaping employees' behaviors in terms of exhibiting ethical behaviors (i.e., follower BI) and engaging in prosocial behaviors that are beneficial for the organization (i.e., OCBO). We thus find strong support for social learning theory as a key theoretical framework for BI research as it can help explain how followers emulate leaders' and organizations' consistency between actions and words and align their extra-role behaviors with what leaders and organizations value.

Moreover, our study shows that the different referents of BI have influence on follower outcomes via differential mechanisms as our results provide support for the mediating role of organizational identification but not for leader identification. Although Simons (2002) had proposed that BI is likely to predict follower behavioral outcomes directly or through its impact on followers' attitudes and social learning theory highlights the role of personal identification in facilitating the internalization of desired behaviors, we did not find support for the mediation of leader identification in our field study (H3a and H5a). While role modeling does not require personal identification, in cases where it is present, the individual perceives an intuitive unity with the role model, which facilitates the influence process (Ashforth et al. 2015). We found a strong relationship between leader BI and follower identification with leader, but this identification did not facilitate leader influence on follower outcomes. A possible reason is that follower BI and OCBO were measured by co-workers in our field study. Although the role-modeling process highlighted in social learning theory may have influenced the person to identify with the leader and internalize the leader's behaviors, this was still not the key mechanism influencing co-workers' perceptions of BI and OCBO. Given that leader identification specifies follower interpersonal relationship with the leader, it is possible that additional mechanisms may play a role for co-worker ratings of follower outcomes (e.g., co-worker trust).

Furthermore, the significant direct effects of leader BI on follower $\mathrm{BI}$ and $\mathrm{OCBO}$ and nonsignificant mediating effect of leader identification suggest that social learning theory is a more appropriate theoretical basis to understand the role of BI in promoting followers' outcomes when the referent is the leader. This finding aligns with Brown et al. 's (2005) conceptualization of ethical leadership in terms of social learning, as ethical leaders are observable role models who can influence followers primarily through role modeling of ethical conduct and normatively appropriate behaviors (Brown and Treviño 2006). On the other hand, when the referent is the organization, the nonsignificant direct effect on follower BI (H2b) but strong mediating effects for organizational identification in this relationship (H3b) suggest that social identity is an important theoretical framework that can help us explain the effects of BI on follower outcomes. Through identifying with the organization and experiencing a sense of belonging (Tajfel and Turner 1979), employees first internalize the organization's values and goals and then act in consistency and in the best interest of the organization. Thus, we find two separate theoretical mechanisms to underlie the effects of different BI foci on follower outcomes. This finding highlights the importance of expanding the lens in BI research to examine different foci and acting entities.

Finally, our research contributes to the BI literature by extending its applications in organizational settings. By 
examining the role of leader and organizational $\mathrm{BI}$ on follower BI and OCBO, we addressed the calls by Davis and Rothstein (2006) and Simons et al. (2015) for further research examining the effects of BI on employees' behaviors. While follower BI is a neglected research area, considering the benefits of followers acting with BI, we showed that leader and organizational BI significantly influence follower BI. Regarding BI- follower OCBs relationship, although there is a strong theoretical support, the empirical examinations have been limited. For example, Dineen et al. (2006) examined leader BI with followers' self-report intention to engage in OCBs and Kannan-Narasimhan and Lawrence (2012) tested leader BI with followers' self-report OCB- helping behavior. By examining the impact of different $\mathrm{BI}$ referents on follower OCBO observed by peers, our research provides additional empirical support for the theoretical link between BI and follower OCBs. Thus, our research sheds light on the role of BI in producing followers' behavioral outcomes that are beneficial for the organization.

\section{Practical Implications}

Our findings are useful to organizations, managers, and employees. Our results show that it is important for organizations and leaders to act consistently with their statements and keep their promises. Employees are carefully monitoring these patterns of behaviors and giving behavioral reactions in terms of adopting BI and engaging in extra-role behaviors toward the organization. For organizations, it is not enough to have value statements, rules and polices that encourages employees to present desirable ethical and prosocial behaviors. Instead, organizations' real actions should strictly follow these statements as well. For leaders, they should be careful to align their words and actions and follow-up their commitments, because followers are taking these leaders as their role models and tending to adopt leader behaviors as their own. In this sense, recruiting leaders who possess BI may serve as the first step in producing ethical behaviors (follower BI) and prosocial behaviors (OCBO) during their interactions with subordinates. Organizations may also encourage such positive outcomes by establishing training programs that involve improving leader-subordinate interactions so as to improve the role-modeling process aimed at optimizing performance across all organizational levels. Moreover, whether the leader and the organization "walk the talk" and fulfill their promises, it may influence leader and organizational identifications of members. Given that follower identifications are crucial in organizational setting as they are related to task performance, citizenship behaviors, and job satisfaction (Lee et al. 2015; Zhang and Chen 2013), organizations are well advised to consider the importance of leader and organizational BI to engender these positive outcomes.

\section{Potential Limitations and Directions for Future Research}

Our study provides several contributions to the literature, but some limitations should be mentioned. First, although we collected data from two different sources, our field study (Study 3 ) is cross-sectional in nature. In a self-rating questionnaire, employees rated their perceptions of leader and organizational BI. In a peer-rating questionnaire, employees rated their co-workers' BI. As such, for the constructs of leader and organizational BI, only the perceptions of single sources were used to test the hypothesized relationships. Given that the BI perception of each stakeholder should be considered independent (Palanski and Yammarino 2009), future research could investigate not only follower perceptions but also other referents' perceptions such as superiors (for leader BI) or customers (for organizational BI).

Second, in light of our theoretical implication that leader BI and organizational BI are separate constructs, we tested organizational BI only with two follower outcomes, follower $\mathrm{BI}$ and OCBO. Future research should explore additional outcomes to see whether organizational BI is indeed effective in an organizational setting. Moreover, examining the mediation of leader and organizational identification with different outcome variables would also help to ascertain a better understanding of these alternative mechanisms which exert the influences of leader and organizational BI on follower outcomes. Finally, Palanski and Yammarino (2009) argued that one of the main problems with integrity research is that the existing theories are relatively narrow in scope as they only focus on a single level of analysis. The present paper also analyzed the data on the individual level, but by examining three different foci, we have offered a more holistic view of the BI construct. Future research could provide a more comprehensive examination of BI by conceptualizing it at team and organizational levels.

\section{Appendix}

\section{Scripts for Study 1 and Study 2 Scenarios}

\section{High Leader Behavioral Integrity Condition}

The following paragraphs describe the typical actions and behaviors of a manager. Please read through this storyline carefully and then answer the questions accordingly.

Background information:

Alex is the manager of a shoe store. Alex has four employees, James, Elizabeth, Mike, and Victoria, who have worked for Alex for at least two years. The manager has full control 
over the store, including assigning tasks for the workers, setting sales goals, and inventory.

At the beginning of this week, on Monday, Alex meets with all the workers. The agenda focuses on a recent problem with meeting the store's sales targets, resumption time, and buying winter shoes from their suppliers.

Here are some selected quotes from this meeting:

Alex: "I would like to start our meeting by discussing our lunchtime. You all know we have lunch from 12 to $1 \mathrm{pm}$. However, we all see that some of us stay longer than $1 \mathrm{~h}$ for lunch, and we have difficulties in dealing with our customers after $1 \mathrm{pm}$. If you all agree, from now on, let's make it our priority, and that, of course, includes me, to be here by $1 \mathrm{pm}$ after our lunch break."

They all agreed.

Alex: "Great. I appreciate your cooperation. Then, we can move to the second point on our agenda. Recently, our sales are down, and I am working to find new strategies to deal with this issue. I really value your thoughts and would love to hear your suggestions on this matter."

Victoria: "I think, as the first step, we should improve our service quality. My suggestion would be to provide a personalized experience to our customers. If we learn about our customers and make customized suggestions, I am sure it will help to increase our sales. It's costless and also very effective. Alex, do you have the list of our customers and the products they purchased? If you can send me that list, then I can work on this."

Alex: "Victoria, that is a great idea. I really like it. Thank you very much for sharing your suggestion. Yes, I do have that list, but it will take me a few days to compile it in a format that would work best for this. I will definitely send you the file by Thursday, and then we can go forward with this strategy."

Mike: "I agree with Victoria; that's a great idea. Alex, there is another issue I would like to discuss regarding the winter inventory. You know that we normally buy 300 shoes from our supplier $X$ for $\$ 90,000$. Although we have not signed a contract yet, we already accepted their offer and promised them to sign a contract that we are going to buy the shoes from them. But, yesterday, supplier Y approached us with an offer of $\$ 70,000$ for the same number of shoes. I know we already promised X, but the offer Y made could really help us meet our profit targets. Can we make an exception to our policies just this one time?".

Alex: "Mike, I understand this is a great opportunity, but we can't do it. We must stick to our policy and keep our promises. Please call Y and tell them that we thank them very much, but we are not able to accept their offer at this time."

Alex: "Thank you very much, everybody, for the productive meeting, I appreciate all of your input."

The end of the meeting.
On Wednesday morning, Alex sent a follow-up email to Victoria. In the email, wrote: "Victoria, your suggestion of providing a personalized experience to our customers is great. I have attached the file, including the information you wanted, as I promised. Please do not hesitate to reach out to me if I can help."

After Victoria read the email, she spoke to other workers. Victoria says, "Alex sent me the list of customers that he/ she promised to send. I can't believe Alex is actually using my suggestion; obviously, Alex values our thoughts, as Alex always says. Besides that, I am pleased to work with Alex because when Alex says he/she is going to do something, Alex definitely does. It is very nice to work with a manager who is always consistent, accountable, and keeps promises."

Elizabeth responds: "Yes, that's pretty typical for Alex. No doubt about it, Alex keeps commitments. You remember, in Monday's meeting, Alex mentioned that our priority is keeping our lunch break exactly to $1 \mathrm{~h}$ and coming back to the store by $1 \mathrm{pm}$. Since then, I've never seen Alex once be late; always here at $1 \mathrm{pm}$, although Alex does not have to do so as the manager. Alex shows the same priorities that he/ she describes; It really says a lot about Alex's character."

\section{Low Leader Behavioral Integrity Condition}

The following paragraphs describe the typical actions and behaviors of a manager. Please read through this storyline carefully and then answer the questions accordingly.

Background information:

Alex is the manager of a shoe store. Alex has four employees, James, Elizabeth, Mike, and Victoria, who have worked for Alex for at least two years. The manager has full control over the store, including assigning tasks for the workers, setting sales goals, and inventory.

At the beginning of this week, on Monday, Alex meets with all the workers. The agenda focuses on a recent problem with meeting the store's sales targets, resumption time, and buying winter shoes from their suppliers.

Here are some selected quotes from this meeting:

Alex: "I would like to start our meeting by discussing our lunchtime. You all know we have lunch from 12 to $1 \mathrm{pm}$. However, we all see that some of us stay longer than $1 \mathrm{~h}$ for lunch, and we have difficulties in dealing with our customers after $1 \mathrm{pm}$. If you all agree, from now on, let's make it our priority, and that, of course, includes me, to be here by $1 \mathrm{pm}$ after our lunch break."

They all agreed.

Alex: "Great. I appreciate your cooperation. Then, we can move to the second point on our agenda. Recently, our sales are down, and I am working to find new strategies to deal with this issue. I really value your thoughts and would love to hear your suggestions on this matter." 
Victoria: "I think, as the first step, we should improve our service quality. My suggestion would be to provide a personalized experience to our customers. If we learn about our customers and make customized suggestions, I am sure it will help to increase our sales. It's costless and also very effective. Alex, do you have the list of our customers and the products they purchased? If you can send me that list, then I can work on this."

Alex: "Victoria, that is a great idea. I really like it. Thank you very much for sharing your suggestion. Yes, I do have that list, but it will take me a few days to compile it in a format that would work best for this. I will definitely send you the file by Thursday, and then we can go forward with this strategy."

Mike: "I agree with Victoria; that's a great idea. Alex, there is another issue I would like to discuss regarding the winter inventory. You know that we normally buy 300 shoes from our supplier $\mathrm{X}$ for $\$ 90,000$. Although we have not signed a contract yet, we already accepted their offer and promised them that we are going to buy the shoes from them. But, yesterday, supplier Y approached us with an offer of $\$ 70,000$ for the same number of shoes. I know we already promised $\mathrm{X}$, but the offer $\mathrm{Y}$ made could really help us meet our profit targets. Can we make an exception to our policies just this one time?".

Alex: "Mike, this is a great opportunity. I don't see why we couldn't make an exception to our policy this time. We are not going to keep our promise to X, but so what? We really need to accept this offer to meet our sales goals. Just tell $\mathrm{X}$ that something came up, and we have to cancel our order. Let's make it seem as if we are acting honestly, though-so let's not let them know about the new deal, OK?".

Alex: "Thank you very much, everybody, for the productive meeting, I appreciate all of your input."

The end of the meeting

On Friday morning, Victoria talked to other workers. Victoria says, "You remember in the last meeting Alex mentioned that he/she would send me the file that includes customers' information by Thursday, Alex didn't send it yet; I am very sure Alex already forgot about it. Alex always does that. Obviously, Alex doesn't value our thoughts, even though he/she always says he/she does. I am really hesitant to keep working for Alex because when Alex says he/she is going to do something, it never happens. It is tough to work with a manager who is always inconsistent, unaccountable, and never keeps promises.

Elizabeth responds: "Yes, that's pretty typical for Alex. No doubt about it, Alex never keeps commitments. You remember, in Monday's meeting, Alex also mentioned that our priority is keeping our lunch break exactly to $1 \mathrm{~h}$ and coming back to the store by $1 \mathrm{pm}$. Alex has never once shown up on time, always late. It is clear that Alex doesn't show the same priorities that he/she describes, it really says a lot about Alex's character."

\section{High Organizational Behavioral Integrity Condition}

The following paragraphs describe the typical actions of an organization. Please read through this information carefully, and then answer the questions about this material as directed.

Consider you are working for $\mathrm{ABC}$, a local architecture company that provides services including creating projects for residential and commercial buildings, and other structures. You have been working for $\mathrm{ABC}$ for more than two years. There is a total of 12 people that work for the company, including you.

Like other architecture companies, many times, you work long hours for a time-sensitive project. The $\mathrm{ABC}$ core values statement states, "We value and reward our workers' effort and time that they spend for us (...) Our priority is to ensure that we always keep our promises" to show their sensitivity to the extra effort and time you spend for the company.

Mostly you work in a team for a project. Recently, you and your three colleagues, as a team, are assigned to a project with a very tight deadline to complete. This project is very important to the company, and they announced that they would reward your team with a $\$ 500$ bonus if you complete it on time. Based on this announcement, the bonuses will be in your account at the end of this month.

As a team, you spent extra time and energy on this project. In the end, you completed it on time. Now, you and your teammates are expecting that $\mathrm{ABC}$ keeps its promise and aligns with the organization values statement that emphasizes how much they appreciate/value the time and effort employees spend for the company.

At the end of the month, the company paid a $\$ 500$ bonus to all team members. That's pretty typical for ABC, no doubt about it, they always keep their promises. You can be sure that when they announce they will do something, they definitely do. Besides that, they always act consistently with the organization values statement that they describe their values. It is very nice to work for a company that is always consistent, accountable, and keeps its promises.

\section{Low Organizational Behavioral Integrity Condition}

The following paragraphs describe the typical actions of an organization. Please read through this information carefully, and then answer the questions about this material as directed.

Consider you are working for $\mathrm{ABC}$, a local architecture company that provides services including creating projects for residential and commercial buildings, and other structures. You have been working for $\mathrm{ABC}$ for more than two 
years. There is a total of 12 people that work for the company, including you.

Like other architecture companies, many times, you work long hours for a time-sensitive project. The $\mathrm{ABC}$ core values statement states, "We value and reward our workers' effort and time that they spend for us (...) Our priority is to ensure that we always keep our promises" to show their sensitivity to the extra effort and time you spend for the company.

Mostly you work in a team for a project. Recently, you and your three colleagues, as a team, are assigned to a project with a very tight deadline to complete. This project is very important to the company, and they announced that they would reward your team with a $\$ 500$ bonus if you complete it on time. Based on this announcement, the bonuses will be in your account at the end of this month.

As a team, you spent a lot of time and energy on this project. In the end, you completed it on time. Now, you and your teammates are expecting that $\mathrm{ABC}$ keeps its promise and aligns with the organization values statement that emphasizes how much they appreciate/value the extra time and effort employees spend for the company.

At the end of the month, ABC sent an email with some excuses that they were not able to pay the $\$ 500$ bonus. That's pretty typical for $\mathrm{ABC}$, no doubt about it, they do not keep their promises. When they announce they will do something, you can never be sure they are going to do. Besides that, they do not act consistently with the organizational values statement that they describe their values. It is tough to work for a company that is inconsistent, unaccountable, and does not keep its promises.

\section{Compliance with Ethical Standards}

Conflict of interest The authors declare that they have no conflicts of interest.

Open Access This article is licensed under a Creative Commons Attribution 4.0 International License, which permits use, sharing, adaptation, distribution and reproduction in any medium or format, as long as you give appropriate credit to the original author(s) and the source, provide a link to the Creative Commons licence, and indicate if changes were made. The images or other third party material in this article are included in the article's Creative Commons licence, unless indicated otherwise in a credit line to the material. If material is not included in the article's Creative Commons licence and your intended use is not permitted by statutory regulation or exceeds the permitted use, you will need to obtain permission directly from the copyright holder. To view a copy of this licence, visit http://creativecommons.org/licenses/by/4.0/.

\section{References}

Alcover, C. M., Rico, R., Turnley, W. H., \& Bolino, M. C. (2017). Understanding the changing nature of psychological contracts in 21st century organizations: A multiple-foci exchange relationships approach and proposed framework. Organizational Psychology Review, 7(1), 4-35.

Aquino, K., \& Reed, I. I. (2002). The self-importance of moral identity. Journal of Personality and Social Psychology, 83(6), 1423-1440.

Ashforth, B. E., \& Mael, F. (1989). Social identity theory and the organization. Academy Of Management Review, 14(1), 20-39.

Ashforth, B. E., Harrison, S. H., \& Corley, K. G. (2008). Identification in organizations: An examination of four fundamental questions. Journal of Management, 34(3), 325-374.

Ashforth, B. E., Schinoff, B. S., \& Rogers, K. M. (2015). "I identify with her", "I identify with him": Unpacking the dynamics of personal identification in organizations. Academy of Management Review, 41(1), 28-60.

Ashton, M. C., \& Lee, K. (2009). The HEXACO-60: A short measure of the major dimensions of personality. Journal of Personality Assessment, 91(4), 340-345.

Avolio, B. J., Gardner, W. L., Walumbwa, F. O., Luthans, F., \& May, D. R. (2004). Unlocking the mask: A look at the process by which authentic leaders impact follower attitudes and behaviors. The Leadership Quarterly, 15(6), 801-823.

Bandura, A. (1977). Self-efficacy: toward a unifying theory of behavioral change. Psychological Review, 84(2), 191.

Bandura, A. (1969). Social-learning theory of identificatory processes. In D. A. Goslin (Ed.), Handbook of socialization theory and research (pp. 213-262). Chicago: Rand McNally.

Bass, B. M., \& Steidlmeier, P. (1999). Ethics, character, and authentic transformational leadership behavior. The Leadership Quarterly, 10(2), 181-217.

Bauman, D. C. (2013). Leadership and the three faces of integrity. The Leadership Quarterly, 24(3), 414-424.

Becker, T. E. (1998). Integrity in organizations: Beyond honesty and conscientiousness. Academy of Management Review, 23(1), 154-161.

Becker, T. E. (2005). Potential problems in the statistical control of variables in organizational research: A qualitative analysis with recommendations. Organizational Research Methods, 8(3), 274-289.

Brown, M. E., \& Treviño, L. K. (2006). Ethical leadership: A review and future directions. The Leadership Quarterly, 17(6), 595-616.

Brown, M. E., Treviño, L. K., \& Harrison, D. A. (2005). Ethical leadership: A social learning perspective for construct development and testing. Organizational Behavior and Human Decision Processes, 97(2), 117-134

Cameron, K. S., Bright, D., \& Caza, A. (2004). Exploring the relationships between organizational virtuousness and performance. American Behavioral Scientist, 47(6), 766-790.

Davis, A. L., \& Rothstein, H. R. (2006). The effects of the perceived behavioral integrity of managers on employee attitudes: A metaanalysis. Journal of Business Ethics, 67(4), 407-419.

De Cremer, D., \& Van Knippenberg, D. (2005). Cooperation as a function of leader self-sacrifice, trust, and identification. Leadership and Organization Development Journal, 26(5), 355-369.

Dineen, B. R., Lewicki, R. J., \& Tomlinson, E. C. (2006). Supervisory guidance and behavioral integrity: Relationships with employee citizenship and deviant behavior. Journal of Applied Psychology, 91(3), 622-635

Dirks, K. T., \& Skarlicki, D. P. (2009). The relationship between being perceived as trustworthy by coworkers and individual performance. Journal of Management, 35(1), 136-157.

Dust, S. B., Resick, C. J., \& Mawritz, M. B. (2014). Transformational leadership, psychological empowerment, and the moderating role of mechanistic-organic contexts. Journal of Organizational Behavior, 35(3), 413-433. 
Dutton, J. E., Dukerich, J. M., \& Harquail, C. V. (1994). Organizational images and member identification. Administrative Science Quarterly, 39(2), 239-263.

Epitropaki, O. (2013). A multi-level investigation of psychological contract breach and organizational identification through the lens of perceived organizational membership: Testing a moderated-mediated model. Journal of Organizational Behavior, 34(1), 65-86.

Ete, Z., Sosik, J. J., Cheong, M., Chun, J. U., Zhu, W., Arenas, F. J., \& Scherer, J. A. (2020). Leader honesty/humility and subordinate organizational citizenship behavior: A case of too-muchof-a-good-thing? Journal of Managerial Psychology. https://doi. org/10.1108/JMP-10-2019-0557.

Ford, R. C., \& Richardson, W. D. (1994). Ethical decision making: A review of the empirical literature. Journal of Business Ethics, 13(3), 205-221.

Fritz, J. H., O'Neil, N. B., Popp, A. M., Williams, C., \& Arnett, R. C. (2012). The influence of supervisory behavioral integrity on intent to comply with organizational ethical standards and organizational commitment. Journal of Business Ethics, 114(2), 251-263.

Hall, R. J., Snell, A. F., \& Foust, M. S. (1999). Item parceling strategies in sem: Investigating the subtle effects of un modeled secondary constructs. Organizational Research Methods, 2(3), 233-256.

Harrison, J. R., \& Mclntosh, P. (1992). Using social learning theory to manage organizational performance. Journal of Managerial Issues, 4(1), 84-105.

Hayes, A. F. (2016). The PROCESS macro for SPSS and SAS.

Hewlin, P. F., Dumas, T. L., \& Burnett, M. F. (2017). To thine own self be true? facades of conformity, values incongruence, and the moderating impact of leader integrity. Academy of Management Journal, 60(1), 178-199.

Hinkin, T. R., \& Schriesheim, C. A. (2015). Leader reinforcement, behavioral integrity, and subordinate outcomes: A social exchange approach. Leadership Quarterly, 26(6), 991-1004.

Hogg, M. A., \& Terry, D. I. (2000). Social identity and self-categorization processes in organizational contexts. Academy of Management Review, 25(1), 121-140.

Holmes, W. T., \& Parker, M. A. (2017). Communication: Empirically testing behavioral integrity and credibility as antecedents for the effective implementation of motivating language. International Journal of Business Communication, 54(1), 70-82.

Ilies, R., Nahrgang, J. D., \& Morgeson, F. P. (2007). Leader-member exchange and citizenship behaviors: A meta-analysis. Journal of Applied Psychology, 92(1), 269.

Jung, H. S., \& Yoon, H. H. (2012). The effects of emotional intelligence on counterproductive work behaviors and organizational citizen behaviors among food and beverage employees in a deluxe hotel. International Journal of Hospitality Management, 31(2), 369-378.

Kacmar, K. M., Bachrach, D. G., Harris, K. J., \& Zivnuska, S. (2011). Fostering good citizenship through ethical leadership: Exploring the moderating role of gender and organizational politics. Journal of Applied Psychology, 96(3), 633-642.

Kannan-Narasimhan, R., \& Lawrence, B. S. (2012). Behavioral integrity: How leader \#ents and trust matter to workplace outcomes. Journal of Business Ethics, 111(2), 165-178.

Kark, R., Shamir, B., \& Chen, G. (2003). The two faces of transformational leadership: Empowerment and dependency. Journal of Applied Psychology, 88(2), 246-255.

Lee, K., \& Allen, N. J. (2002). Organizational citizenship behavior and workplace deviance: The role of affect and cognitions. The Journal of Applied Psychology, 87(1), 131-142.

Lee, E. S., Park, T. Y., \& Koo, B. (2015). Identifying organizational identification as a basis for attitudes and behaviors: A metaanalytic review. Psychological Bulletin, 141(5), 1049-1080.
Leroy, H., Palanski, M. E., \& Simons, T. (2012). Authentic leadership and behavioral integrity as drivers of follower commitment and performance. Journal of Business Ethics, 107(3), 255-264.

Mael, F. A., \& Ashforth, B. E. (1992). Alumni and their alma mater: A partial test of the reformulated model of organizational identification. Journal of Organizational Behavior, 13, 103-123.

Mael, F. A., \& Tetrick, L. E. (1992). Identifying organizational identification. Educational and Psychological Measurement, 52(4), 813-824.

Marstand, A. F., Epitropaki, O., van Knippenberg, D., \& Martin, R. (2020). Leader and organizational identification and organizational citizenship behaviors: Examining cross-lagged relationships and the moderating role of collective identity orientation. Human Relations. https://doi.org/10.1177/0018726720938118.

Mayer, D. M., Kuenzi, M., Greenbaum, R., Bardes, M., \& Salvador, R. B. (2009). How low does ethical leadership flow? Test of a trickle-down model. Organizational Behavior and Human Decision Processes, 108(1), 1-13.

Miao, Q., \& Zhou, J. (2020). Corporate hypocrisy and counterproductive work behavior: A moderated mediation model of organizational identification and perceived importance of CSR. Sustainability, 12(5), 1847.

Organ, D. W., \& Ryan, K. (1995). A meta-analytic review of attitudinal and dispositional predictors of organizational citizenship behavior. Personnel Psychology, 48(4), 775-802.

Organ, D. W. (1997). Organizational citizenship behavior: It's construct clean-up time. Human Performance, 10(2), 85-97.

Palanski, M. E., \& Yammarino, F. J. (2007). Integrity and leadership: Clearing the conceptual confusion. European Management Journal, 25(3), 171-184.

Palanski, M. E., \& Yammarino, F. J. (2009). Integrity and leadership: A multi-level conceptual framework. Leadership Quarterly, 20(3), 405-420.

Palanski, M. E., \& Yammarino, F. J. (2011). Impact of behavioral integrity on follower job performance: A three-study examination. Leadership Quarterly, 22(4), 765-786.

Palanski, M. E., Cullen, K. L., Gentry, W. A., \& Nichols, C. M. (2015). Virtuous leadership: Exploring the effects of leader courage and behavioral integrity on leader performance and image. Journal of Business Ethics, 132(2), 297-310.

Parry, K. W., \& Proctor-Thomson, S. B. (2002). Perceived integrity of transformational leaders in Organizational settings. Journal of Business Ethics, 35(2), 75-96.

Pratt, M. G. (1998). Central questions in organizational identification. Identity in Organizations, 24(3), 171-207.

Preacher, K. J., \& Hayes, A. F. (2008). Asymptotic and resampling strategies for assessing and comparing indirect effects in multiple mediator models. Behavior Research Methods, 40(3), 879-891.

Restubog, S. L. D., Hornsey, M. J., Bordia, P., \& Esposo, S. R. (2008). Effects of psychological contract breach on organizational citizenship behaviour: Insights from the group value model. Journal of Management Studies, 45(8), 1377-1400.

Riketta, M., \& Van Dick, R. (2005). Foci of attachment in organizations: A meta-analytic comparison of the strength and correlates of workgroup versus organizational identification and commitment. Journal of Vocational Behavior, 67(3), 490-510.

Robinson, S. L. (1996). Trust and breach of the psychological contract. Administrative Science Quarterly, 20, 574-599.

Rogers, W. M., \& Schmitt, N. (2004). Parameter recovery and model fit using multidimensional composites: A comparison of four empirical parceling algorithms. Multivariate Behavioral Research, 39(3), 379-412.

Schrodt, P. (2002). The relationship between organizational identification and organizational culture: Employee perceptions of culture 
and identification in a retail sales organization. Communication Studies, 53(2), 189-202.

Shore, L. M., \& Coyle-Shapiro, J. A. M. (2003). New developments in the employee-organization relationship. Journal of Organizational Behavior, 24(5), 443-450.

Simons, T. (2002). Behavioral integrity: the perceived alignment between managers' words and deeds as a research focus. Organization Science, 13(1), 18-35.

Simons, T., Friedman, R., Liu, L. A., \& McLean Parks, J. (2007). Racial differences in sensitivity to behavioral integrity: Attitudinal consequences, in-group effects, and "trickle down" among Black and non-Black employees. Journal of Applied Psychology, 92(3), 650-665.

Simons, T., Leroy, H., Collewaert, V., \& Masschelein, S. (2015). How leader alignment of words and deeds affects followers: A metaanalysis of behavioral integrity research. Journal of Business Ethics, 132(4), 831-844.

Simons, T., Tomlinson, E., \& Leroy, H. (2011). Research on behavioral integrity: A promising construct for positive organizational scholarship. In K. S. Cameron \& G. M. Spreitzer (Eds.), Handbook of positive organizational scholarship. Oxford: Oxford University Press.

Smidts, A., Pruyn, A. T. H., \& Van Riel, C. B. (2001). The impact of employee communication and perceived external prestige on organizational identification. Academy of Management Journal, 44(5), 1051-1062.

Sluss, D. M., \& Ashforth, B. E. (2007). Relational identity and identification: Defining ourselves through work relationships. Academy of Management Review, 32(1), 9-32.

Sosik, J. J., Chun, J. U., Ete, Z., Arenas, F. J., \& Scherer, J. A. (2019). Self-control puts character into action: Examining how leader character strengths and ethical leadership relate to leader outcomes. Journal of Business Ethics, 160(3), 765-781.

Tajfel, H., \& Turner, J. C. (1979). An integrative theory of intergroup conflict. In W. G. Austin \& S. Worchel (Eds.), The social psychology of inter-group relations (pp. 33-47). Brooks/Cole: Monterey, CA.

Tekleab, A. G., \& Chiaburu, D. S. (2011). Social exchange: Empirical examination of form and focus. Journal of Business Research, 64(5), 460-466.
Treviño, L. K., Butterfield, K. D., \& McCabe, D. L. (1998). The ethical context in organizations: Influences on employee attitudes and behaviors. Business Ethics Quarterly, 8(3), 447-476.

Tsiu, A. S., \& O'Reilly, C. A. (1989). Beyond simple demographic effects: The importance of relational demography in supervisor-subordinate dyads. Academy of Management Journal, 32, $402-423$.

Turner, J. C., Hogg, M. A., Oakes, P. J., Reicher, S. D., \& Wetherell, M. S. (1987). Rediscovering the social group: A self-categorization theory. Oxford: Basil Blackwell.

Vogelgesang, G. R., Leroy, H., \& Avolio, B. J. (2013). The mediating effects of leader integrity with transparency in communication and work engagement/performance. Leadership Quarterly, 24(3), 405-413.

Walumbwa, F. O., \& Schaubroeck, J. (2009). Leader personality traits and employee voice behavior: Mediating roles of ethical leadership and work group psychological safety. Journal of Applied Psychology, 94(5), 1275-1286.

Wang, Z., Xing, L., Xu, H., \& Hannah, S. T. (2019). Not all followers socially learn from ethical leaders: The roles of followers' moral identity and leader identification in the ethical leadership process. Journal of Business Ethics, 48, 1-21.

Williams, L. J., \& Anderson, S. E. (1991). Job satisfaction and organizational commitment as predictors of organizational citizenship and in-role behaviors. Journal of Management, 17(3), 601-617.

Yaffe, T., \& Kark, R. (2011). Leading by example: the case of leader ocb. Journal of Applied Psychology, 96(4), 806-826.

Zhang, Y., \& Chen, C. C. (2013). Developmental leadership and organizational citizenship behavior: Mediating effects of self-determination, supervisor identification, and organizational identification. The Leadership Quarterly, 24(4), 534-543.

Zhao, X., Lynch, J. G., Jr., \& Chen, Q. (2010). Reconsidering Baron and Kenny: Myths and truths about mediation analysis. Journal of Consumer Research, 37(2), 197-206.

Publisher's Note Springer Nature remains neutral with regard to jurisdictional claims in published maps and institutional affiliations. 